\title{
REFLEXÕES SOBRE A ÉTICA E A CENSURA NO TEATRO DE MaQuiavel
}

\author{
Riflessioni su Etica e Censura nel Teatro di \\ Machiavelli
}

\section{Reflections on Ethics and Censorship on Maquiavelli's Theater}

\author{
Priscila Nogueira da Rocha*
}

RESUMO: As relações humanas estão no centro de cada escolha moral ou ética. Nicolau Maquiavel (1469-1527) traz em seu teatro representações complexas, significativas e emocionais da experiência humana. Esta diversidade de temas, ações e emoções contribui para a reflexão sobre as escolhas pessoais, a sociedade e o tempo em que vivia. Porque então Mandragola (1518), obra prima do teatro dramático italiano, foi censurada por tantos séculos? Quando há censura, esta visa a imposição de uma moral privada no espaço de todos, evidenciando a vontade de parte da sociedade em se afirmar como legítimos representantes da "verdade" que se identifica com suas crenças e estilo de vida. A ética, ao contrário, é uma pesquisa da verdade através da reflexão e do confronto. A ética demanda liberdade de escolha pelo indivíduo em seu modo de agir, conforme seu conceito. Se não existe confronto, não existe vontade possível. O questionamento ético começa desconstruindo os lugares sagrados da literatura e da crítica canônica. Trata-se de colocar sob suspeita os processos de semiotização da realidade, que reduzem o outro a uma representação homogeneizante. A partir disso, o artigo apresentará uma reflexão sobre a censura aplicada pela Igreja aos textos teatrais de Maquiavel, sob a alegação de que sua obra se oporia às ideias e conceitos difundidos pela instituição. Pretende-se demonstrar que, mais que discordar do conteúdo das obras, o objetivo era impedir a propagação da visão crítica de Maquiavel, ainda que isso não tivesse efeito prático sobre a sociedade e as relações humanas.

PALAVRAS-CHAVE: Maquiavel; Mandragola; ética; moral; censura.

* Universidade Federal do Rio de Janeiro (UFRJ)

pnrocha@gmail.com - (ORCID: 0000-0003-2200-6959)

DOI: http://dx.doi.org/10.11606/issn.2238-8281.v0i41p84-97 
RIASSUNTO: I rapporti umani sono al centro di ogni scelta morale o etica. Niccolò Machiavelli (1469-1527) mostra nel suo teatro rappresentazioni complesse, significative ed emotive dell'esperienza umana. Questa diversità di temi, azioni ed emozioni ha contribuito alla riflessione sulle scelte personali, sulla società e suo tempo. Perché allora Mandragola (1518), capolavoro assoluto del teatro italiano, fu censurata per tanti secoli? Quando c'è censura, è da intendersi come un'imposizione di una morale privata nello spazio di tutti, mostrando la volontà di una parte della società di affermarsi come legittima rappresentante della "verità" che si identifica con le sue convinzioni e stile di vita. L'etica, inversamente, è una ricerca della verità attraverso riflessione e confronto. L'etica richiede libertà di scelta degli individui nel loro modo di agire, secondo il loro punto di vista. Se non c'è confronto, non c'è volontà possibile. La messa in discussione etica inizia decostruendo i luoghi sacri della letteratura e della critica canonica. Trattasi di mettere in dubbio i processi di semiotizzazione della realtà, che riducono l'altro a rappresentazione omogeneizzante. In base a ciò che si è visto, il saggio presenterà una riflessione sulla censura applicata dalla Chiesa ai testi teatrali di Machiavelli, con l'accusa che il suo lavoro si sarebbe opposto alle idee e ai concetti diffusi dall'istituzione. Si vuole dimostrare che, più che in disaccordo con il contenuto delle opere, l'obiettivo è stato quello di impedire la propagazione della visione critica di Machiavelli, anche se questa non ha avuto effetti concreti sulla società e sui rapporti umani.

PAROLE CHIAVE: Machiavelli; Mandragola; etica; morale; censura.

ABSTRACT: Human relations are at the center of every moral or ethical choice. Niccolò Machiavelli (1469-1527) brings in his theater complex, significant and emotional representations of the human experience. This diversity of themes, actions and emotions contributes to the reflection on his personal choices and the society by the time he lived. Why then was Mandragola (1518), a masterpiece of Italian theater, censored for so many centuries? When there is censorship, it usually aims to impose a private morality in everyone's space, showing the willingness of a part of the society to assert itself as legitimate representatives of that "truth" which matches their beliefs and lifestyle. Ethics, on the opposite, is a search for the truth through reflection and confrontation. Ethics demands freedom of choice for the individual to act accordingly to its concept. If there is no confrontation, there is no possible will. Ethical questioning begins by deconstructing the sacred places of literature and canonical criticism. It is a matter of putting under suspicion the processes of semiotization of reality, which reduce the other to a homogenizing representation. Based on that, this article will present a reflection on the censorship applied by the Church to Machiavelli's theatrical texts, under the allega- 
timon that his work would oppose the ideas and concepts disseminated by the institution. It intends to demonstrate that, beyond disagreeing with the content of his works, the objective was to prevent the propagation of Machiavelli's critical vision, even though it had no practical effect on society and human relations.

KEYWORDS: Machiavelli; Mandragola; ethics; morality; censorship. 


\section{Introdução}

Muitas vezes, para defender um comportamento, escutamos a frase: "Os fins justificam os meios". Esta frase, embora popularmente atribuída a Maquiavel, jamais chegou a ser por ele proferida, nem consta de nenhum de seus escritos. A interpretação que levou a estabelecer esta falsa citação tem sua origem em uma interpretação de Il Principe, obra que propõe a separação entre a moral religiosa e a ética política e na qual o autor indica que, para manter o poder, o Príncipe deveria desenvolver características tidas como antiéticas, como a crueldade e hipocrisia. Sugere ainda que, com o intuito de se alcançar determinado objetivo, seria aceitável tomar qualquer atitude. Muitos leitores, ao longo da história, passaram a se aproveitar dessa frase para justificar suas ações sem medir esforços, o que cunhou a expressão "maquiavélico(a)" significando pessoa traiçoeira, ardilosa, cínica, que para atingir seu objetivo usam os artifícios da má-fé e da mentira.

Inicialmente utilizada estritamente no contexto político, a frase que se tornou dito popular acabou por ser transposta para todas as áreas da vida cotidiana, levando à defesa da máxima de que tudo seria permitido se visasse a um "bem maior", o que poderia significar qualquer objetivo que fosse conveniente, ainda que tais atitudes pudessem ser consideradas reprováveis no âmbito da ética e da moral. É possível, portanto, extrapolar o conceito inicial, restrito à política, e a partir disso perceber que mesmo em sua comédia mais célebre, Mandragola, Maquiavel expõe que a sociedade, e por fim o próprio ser humano, se comporta desta mesma maneira, ainda que de forma mais velada.

\section{Ética e moral em Maquiavel}

Antes de nos aprofundarmos na obra em si, é importante estabelecer os conceitos de ética e moral nos quais está baseada a análise deste artigo. Dificilmente se dissocia ética de moral, porém, apesar de possuírem algumas similaridades quanto ao significado, trazem algumas características diferentes entre si, possuindo elementos que são necessários para a formação do comportamento do ser humano na sociedade.

Ética vem do grego e se refere a tudo que pertence ao ethos, significando bom costume, superior, portador de caráter. Ética seria, portanto, um conjunto de conhecimentos extraídos da investigação do comportamento humano ao tentar explicar as regras morais de forma racional, fundamentada, científica e teórica, ou seja, é uma reflexão sobre a moral. Podemos, analogamente, definir moral como o conjunto de regras aplicadas ao cotidiano e usadas continuamente por cada cidadão. Essas regras orientam cada indivíduo, norteando suas ações e seus julgamentos sobre o que é moral ou imoral, certo ou errado, bom ou mau. Diferenciam-se, portanto, ética e moral, pois esta se fundamenta na obediência a costumes e hábitos recebidos, ao contrário da ética, que busca fundamentar os valores e princípios morais de uma sociedade exclusivamente pela razão. Na filosofia clássica, a ética não se resumia à moral, mas buscava a fundamentação 
teórica para encontrar melhor modo de viver e conviver, isto é, a busca do melhor estilo de vida, tanto na vida privada quanto em público. No sentido prático, porém, a finalidade de ambas é muito semelhante, sendo responsáveis por construir as bases que vão guiar a conduta do homem, determinando o seu caráter, altruísmo e virtudes, e por ensinar a melhor forma de agir e de se comportar em sociedade. Para sintetizar, utilizemos o pensamento de Coimbra (2002, p. 75): “A Ética significa ciência da moral, quer dizer, seria a construção intelectual, organizada pela mente humana sobre a moral. Esta seria, pois, o seu objeto".

Importante deixar claro que Maquiavel não era moralista e também não procurou redefinir valores. Mesmo assim, Il Principe provocou escândalo por parecer atacar de uma forma crua crenças e valores que sempre constituíram o núcleo da moral cristã. Ou seja, para Maquiavel existem duas éticas diferentes: aquela cristã, benéfica para a salvação da alma, (que traz como mote ser bom sempre, nunca mentir, não usar "máscaras sociais"); em contraste com a ética política, necessária para salvar o Estado, na qual se pode inferir que a pessoa pode ser má quando houver necessidade, mentir se e quando a situação exigir, e parecer sempre bom e piedoso. Resumindo, para o autor, a ética política é utilitária por considerar morais todos os atos úteis à comunidade, porém imorais se levarem em consideração somente a satisfação pessoal do indivíduo, entrando em conflito com os interesses do coletivo.

\section{Maquiavel autor}

Embora muito conhecido por sua teoria política, Maquiavel foi um grande escritor de peças de teatro, poesias, da história de Florença, porém jamais escreve nenhuma obra em que se coloque no papel de teólogo, não por indiferença, mas por enxergar a religião apenas como um meio no sentido de determinar como um representante político deve se comportar com o povo. Está construída apenas no plano político e não no teológico.

Muito se escuta sobre a atemporalidade das grandes obras, que nunca deixam de ser referência mesmo após o passar de tantos séculos, característica patente dos textos de Maquiavel não só por sua obra mais conhecida, Il Principe, em que expõe os argumentos e princípios para um governante perfeito, como também nas suas comédias, principalmente em Mandragola, que mostra na sua trama a corrupção e a falência de instituições das quais se esperaria uma postura ética, como por exemplo a Igreja e a família, e que ao pensar em seus interesses pessoais, vão se aliar aos demais, não pensando em moralidade ou boas intenções, mas do proveito que poderão tirar da ajuda prestada. Apesar de escrita há 500 anos, a obra se mostra atual como poucas em nossos dias, firmando-se como a grande comédia de Maquiavel e do Cinquecento italiano. E é este status de principal obra do autor, ao menos dentro do gênero e do período, que motiva a escolha de Mandragola como ponto inicial da análise que se pretende realizar neste artigo. 


\section{Análise de Mandragola}

A obra se desenvolve em torno do tema da zombaria ${ }^{1}$, especialmente na relação entre os personagens de Nicia, o tolo, e Ligurio, o artífice. Também o tema do amor, representado pelos personagens de Callimaco e Lucrezia, é amplamente explorado. O enredo de Mandragola se inicia no diálogo entre o jovem florentino Callimaco Guadagni e seu criado, Siro, discutindo sua saída de Paris, onde teria ouvido sobre os encantos de uma mulher, tida como a mais bela e virtuosa de Florença, de nome Lucrezia, e por ela se apaixona, mesmo sem nunca a ter visto. Motivado pela paixão, Callimaco retorna à sua terra natal em companhia de seu servo. Apesar de saber que a moça era casada, ele tem o firme propósito de conquistá-la, ainda que apenas por uma noite. O marido de Lucrezia, Nicia Calfucci, embora detentor do título de doutor das leis, é bobo e ignorante, e bem mais velho do que a esposa. A relação do casal tem ainda um ponto embaraçoso: o fato de não conseguirem procriar. E é em torno desta questão que a comédia desenrola suas cenas. Ao chegar a Florença, Callimaco recorre à ajuda de Ligurio, um astuto mediador que idealiza o plano, baseado em um engano, que permitirá ao jovem atingir seu objetivo de ter uma noite de amor com Lucrezia. Valendo-se da estupidez do marido, e conhecendo sua vontade de gerar um herdeiro, planejam que Callimaco, em vestes de médico, usará desse fingimento para convencer Nicia, se utilizando de um "latim" tão forjado como a sua vestimenta de clínico. A sugestão é que uma poção feita com a raiz da mandrágora faria com que Lucrezia pudesse engravidar, e é da explicação falaciosa sobre como o chá desta erva deverá ser consumido, e quais seriam seus efeitos, que se tece a comédia de Maquiavel: o consumo do chá "curaria" Lucrezia, mas causaria a morte súbita do primeiro homem que se deitasse com a mulher após a ingestão da bebida. Após ter relatado essa contraindicação, Callimaco, ainda em vestes de médico, sugere que eles capturem um jovem na estrada para obrigá-lo a se relacionar com Lucrezia logo após o consumo do chá e, assim tomar para si o veneno da planta. O plano, entretanto, era que o próprio Callimaco, agora disfarçado de vagabundo, seria o "infeliz" a encontrar a morte por um bem maior. Apesar de assustado com as explicações do falso médico, Nicia quer tanto ter filhos que, por fim, aceita o estratagema proposto. Resta então apenas uma dificuldade a ser superada: convencer a jovem esposa a se deitar com outro homem, tendo em vista que, até este momento, Lucrezia era apresentada como uma dama muito virtuosa. A solução para esse dilema é trazida pela entrada em cena de seu confessor, Fra Timoteo, que aceita vender seu aconselhamento religioso para que o ardil tenha êxito, sendo auxiliado ainda pela própria mãe de Lucrezia, Sostrata. Por fim, o religioso e a mãe convencem a jovem senhora a obedecer ao desejo do esposo. O plano segue como previsto, o amante é colocado na cama de Lucrezia pelo próprio marido, e esta, que inicialmente não aceitara muito bem o plano que julgava ser de Nicia, após ter ouvido a declaração de amor de Callimaco, se entrega ao adultério, sem que seu marido suspeite ter sido enganado.

No dia seguinte à farsa proposta na obra, é apresentado um suposto "final feliz", no qual 
todos alcançam seus objetivos, porém todos enganam e são enganados, e fica evidente que cada personagem tem uma segunda face, ou véu. Na cena final, todos se encontram na igreja para serem abençoados. Um final "feliz" ao primeiro olhar, porém mais trágico que alegre, gerando uma sensação nova e desconhecida nas comédias, culminando com um encerramento diferente de suas antecessoras, não apresentando no final da peça a tradicional festa, com todos os impasses resolvidos, os enganos desfeitos, os personagens bons triunfando e os maus pagando caro por seus atos. Pelo contrário, em Mandragola o que se vê é uma ruptura desses padrões: os personagens, embora simples e quase "caricatos" (mais arquétipos de seu papel social do que propriamente indivíduos), são dúbios, não podendo ser facilmente identificados como bons ou maus, e todas as ações que a princípio seriam entendidas como negativas, tais como mentiras, corrupção e adultério, são justificadas para um "bem" maior, onde o engano acaba sendo responsável pelo status final, no qual todos estão felizes: Fra Timoteo com sua recompensa, Messer Nicia com a cura da infertilidade de sua esposa, Lucrezia por ter encontrado um amante que a satisfaz mais do que o marido, Callimaco pela satisfação de seu desejo pessoal, e pela perspectiva do futuro com a amante, e Ligurio pelo prazer intelectual de ter sido bem sucedido em sua manipulação. O senso é de que o egoísmo extremado prevaleça: cada personagem só enxerga os próprios objetivos, sem nenhum senso de coletividade ou empatia. Tudo se resolve através da manipulação, e o próprio fato de que este estado de coisas positivas tenha sido gerado por um engano já evidencia a conhecida visão da ideologia maquiavélica - se o fim é positivo, qualquer meio para obtê-lo é aceitável, mesmo o engano.

Grande parte da originalidade de Mandragola deriva do fato de Maquiavel fazer uma paródia de si mesmo, mostrando todo o seu pessimismo e expondo a decadência política de sua amada Florença. Caracterizada como uma zombaria erótica, porém impelida para além da diversão proposta nas novelas de Boccaccio, incluindo assuntos delicados como a profanação do sacro e da instituição familiar. Como verificado em Pulce (1867, p. 422), nem todos consideravam esta comédia uma obra de arte, e não a aconselhavam aos seus leitores. Pulce, em sua obra, critica não somente Maquiavel por escrevê-la, mas também ao Papa Leão X, que comovido pelas comédias Mandragola e Calandria, as ouvia em seu aposento no Vaticano. Ridolfi (1978, p. 280) nos conta que apesar de Maquiavel também ter oferecido Il Principe para o recém-eleito Papa, foi com Mandragola que teve o seu reconhecimento, uma vez que para a representação de 1520 em Roma foi construído um teatro: Leone era uomo da conquistarsi piú con una grassa commedia che con un Principe. No que diz respeito a Maquiavel, afirma que suas obras poderiam ser representadas com honra, se o secretário tivesse escolhido assuntos menos licenciosos e inadequados aos costumes da época.

Pulce (1867, p. 422) resume a obra alegando uma semelhança com Aristófanes, e acrescenta que Maquiavel pretende flagelar, usando a sátira, alguns cidadãos que se utilizam de falsos religiosos que, por meio de um ministério sagrado, se prestam a favorecer os enganos de homens perversos. Ao descrever os personagens, afirma que um frei e um falso médico devem persuadir uma senhora honesta e pura a beber uma poção de mandrágora, através de preceitos lascivos 
para ter um filho. Apesar da opinião do crítico, a graciosidade com que a ação é contada e o estilo utilizado fizeram com que o Papa Leão X, tendo-a visto quando era cardeal em Florença, quis revê-la quando se tornou Papa.

Ao saber de todo o plano, Nicia não aceita inicialmente que sua mulher mantenha relações com outro homem, depois se preocupa se não pode ser descoberto pelos Oito (referência aos Otto di guardia di $\mathrm{Balia}^{2}$ ) por cometer um crime, porém cede ao final, deixando claro que não se importa se alguém viesse a morrer, desde que alcance seu objetivo e as aparências sejam mantidas. Onde estaria a ética e a moralidade desse doutor? Maquiavel revela também, de forma ainda mais grave, todo o seu escárnio e sua ironia no comportamento dos padres. Callimaco usa uma frase que sintetiza o pensamento do autor: Oh, frati! Conoscine uno e li conosci tutti (MACHIAVELLI, 2006, p. 80). Isso seria verificado principalmente no comportamento de Fra Timoteo: Maquiavel faz questão de mostrar como a Igreja Católica Romana, portadora do discurso da moralidade da época, era também, uma vez que formada por homens, ambiciosa e egoísta. Muito do seu sarcasmo fica evidente na fala de Fra Timoteo, como por exemplo no monólogo a seguir:

Ed ho cercato di far passare il tempo in varie occupazioni: dissi mattutino, lessi una vita dei Santi Padri, andai in chiesa e accesi una lampada che era spenta, mutai un velo a una Nostra Signora che fa miracoli. Quante volte ho detto a questi frati che la tengano pulita! E si meravigliano poi se la devozione manca! Io mi ricordo che c'erano cinquecento immagini, e oggi non ve ne sono venti. Questo è dipeso da noi, che non abbiano saputo mantenerne la reputazione. Noi eravamo soliti ogni sera dopo la compieta andare in processione e farvi cantare ogni sabato le lodi. Noi stessi facevamo sempre voto qui, perché si vedessero le immagini fresche; e nelle confessioni invitavamo gli uomini e le donne a far voti. Ora non si fa nulla di queste cose, e poi ci meravigliamo se le cose vanno fredde! Oh, quanto poco cervello hanno questi miei frati! (MACHIAVELLI, 2006, p. 120)

\section{Visão da Igreja e da Religiosidade}

A partir da análise da obra, surge o questionamento se haveria motivos adicionais para a censura, além da mera crítica direta à Instituição Eclesiástica, personificada em Fra Timoteo, uma vez que há na obra um pensamento crítico bastante contundente e conflitante com os conceitos defendidos pela igreja do que seriam os "bons costumes" a serem vivenciados.

Assim, retomando o argumento da comédia, a plateia ria não só das tolices de Messer Nicia, como também dos argumentos de Fra Timoteo e, inconscientemente ou não, estavam rindo da própria Igreja. Esta posição é confirmada por Asor Rosa (2009, p. 284), que vislumbra a crítica na obra a partir do tom anticlerical, da sátira aos costumes florentinos da época e do apego ao luxo e ao dinheiro. Pode-se ver isso ainda mais claramente na alteração dos posicionamentos

2 Conselho dos Oito de Guarda: antiga magistratura florentina que lidava com os assuntos criminais e policiais da República de Florença antes e depois do Granducato. 
diante da moralidade católica cristã presente nessa obra de Maquiavel, quando a figura de Fra Timoteo usa de argumentos supostamente religiosos, porém obviamente distorcidos para alcançar o seu objetivo, visando apenas seu benefício pessoal, provocando o riso, pois dele se esperaria justamente o oposto, dado seu papel sacerdotal. Fica claro ainda, no discurso de Timoteo, toda a sua hipocrisia e seu desrespeito com as mulheres, e como passara por cima dos valores da Igreja para obter retorno financeiro. Este comportamento também pode ser observado quando o frei abusa de sua habilidade dialética nas afirmações "bíblicas" para convencer Lucrezia a contrariar suas convicções e participar do ato que estava sendo arquitetado. Primeiro afirma que no ato pecaminoso quem peca é a vontade, e não o corpo. Assim, mesmo com a traição, ela continuaria virtuosa, pois somente seu corpo seria entregue a outro homem, não tendo ela, portanto, cometido nenhum pecado, por não existir interesse de sua parte.

Io voglio tornare a quello, ch'io dicevo prima. Voi avete, quanto alla conscienzia, a pigliare questa generalità: che dove è un bene certo e un male incerto, non si debbe mai lasciare quel bene per paura di quel male. Qui è un bene certo: che voi ingraviderete, acquisterete una anima a messer Domenedio. El male incerto è che colui che iacerà con voi dopo la pozione si muoia. È si truova anche di quelli che non muoiano, ma perché la cosa è dubia, però è bene che messer Nicia non corra quel pericolo. Quanto allo atto che sia peccato, questo è una favola: perché la volontà è quella che pecca, non el corpo; e la cagion del peccato è dispiacere al marito, e voi li compiacete; pigliarne piacere, e voi ne avete dispiacere. Oltr'a di questo, el fine si ha a riguardare in tutte le cose: el fine vostro si è riempiere una sedia in paradiso, $e$ contentare el marito vostro. (MACHIAVELLI, 2006, p. 79-81)

O discurso do frei à Lucrezia não visa simplesmente fazê-la dormir com um desconhecido, mas convencê-la a não pensar muito sobre isso e mostrar que o pecado em que Lucrezia acredita, nada mais seria que uma boa ação. Para convencê-la, fala sobre a distinção entre vontade e culpa. Diz que existe um bem - o filho vindouro - e um mal - a morte do suposto vagabundo - mas que ela deveria ficar tranquila, pois não estaria cometendo pecado algum ao agradar o marido. Porém, mais relevante que isso, coloca a vontade do homem acima dos preceitos da moral católica cristã (ou, por outro enfoque, que essa vontade se moldaria à do homem).

É importante ressaltar que a presença de padres é uma inovação na comédia maquiaveliana, uma vez que não existia nas comédias latinas, e Maquiavel se aproveita disso para apresentar seu Fra Timoteo como um religioso que só tem interesse nos ganhos, considerando as mulheres úteis apenas para ser manipuladas e angariar esmolas.

Além de tentar - e conseguir - persuadir Lucrezia a trair seu marido, encontramos outros fatores que questionariam a moralidade do Frei, dentre eles a aceitação da prática da sodomia e a absolvição em troca de esmolas, e até mesmo a participação em um aborto em uma menina que teria engravidado dentro de um monastério. Fra Timoteo aceita fazer o que lhe é pedido, naturalmente em troca de uma compensação financeira (carità): Sia così, con il nome di Dio. Fate ciò che volete, e, per Dio e per carità, fate anche il resto. Ditemi il monastero, 
datemi la pozione, e, se vi pare, questi danari, da poter incominciare a fare qualche bene (MACHIAVELLI, 2006, p. 68-69). Se Timoteo não se recusara a levar uma poção para fazer com que a menina aborte, ou seja, aceitou uma intervenção pagã para interromper um processo supostamente sagrado (uma gravidez), não haveria dificuldades em aceitar outra para que uma criança possa ser gerada, novamente sempre em troca de algum favor monetário. Maquiavel evidencia com isso a corrupção do frei, que aceita usar de poções profanas em troca de dinheiro, representando, no olhar do autor, a igreja daquele tempo, sempre sensível à oferta dos fiéis. Fra Timoteo, isolado na cena, é o maior enganador de todos, pois age na consciência moral e religiosa de Lucrezia e se utiliza do sagrado para seu convencimento.

\section{Censura}

Apesar de sofrer censura ainda no século XVI, ao se tornar, em 1556, uma das obras proibidas pela Igreja, por conter cenas de adultério e por difamar a instituição eclesiástica, continuava sendo comercializada, e apesar do gênero teatral, era utilizada principalmente como texto literário. O retrato desprezível de Fra Timoteo seria o principal motivo para que a obra tenha entrado no Index dos livros proibidos e aparecesse também na lista dos autores quórum libri et scripta omnia prohibentur, tentativa posterior para apagar a voz perigosamente crítica do autor para com a Igreja e com a sociedade em geral. O Index Librorum Prohibitorum ou Index Expurgatorius foi uma lista de publicações proibidas pela Santa Sé, por serem consideradas heréticas e/ou de várias linhas de pensamentos divergentes, desde o início do Cristianismo, mas que se acirrou principalmente por conta das divergências com os Protestantes e Iluministas. Apesar disso, existem comprovações de que a obra Mandragola continuou sendo publicada, e circulava de várias maneiras, e sabe-se que autores como Goldoni e Pirandello tiveram acesso à leitura da obra, ainda que por meios clandestinos.

Um dos argumentos oferecidos à época, defendido pelo cardeal Reginald Pole (in PROCACCI, 1995, p. 87), entre outros, define Maquiavel como um inimigo do gênero humano e que Il Principe teria sido escrito com o dedo do diabo. Sabe-se que Maquiavel, através de seus relatos, também se sentia cristão, mas de uma maneira toda sua, não seguindo o modelo romano e portando uma ideia bem diferente do que entendemos por religiosidade. $\mathrm{O}$ autor sempre afirmou que amava mais a pátria que a própria alma, pois seria esse o caminho para ser um bom cristão, de praticar o valor da caridade e obter a salvação eterna. Uma vez encontrado o verdadeiro caminho, todo o resto - confissões, missas, jejuns, inferno, paraíso, etc. - teria pouca importância. Por conta disso, muitos o definiam ateu, porém não existem estudos que mostrem que Maquiavel não acreditava em Deus.

Dentre idas e vindas, somente em 1953 a obra foi novamente representada de fato e, a partir disso, seguiu como um evento memorável, sendo apresentada em 142 sessões naquela temporada somente em Roma, tendo seu sucesso derivado do respeito filológico ao texto e à cena, e que até hoje, ainda que muitas vezes adaptada, continua a fazer muito sucesso, tanto que 
podemos encontrar também versões em outras mídias, como cinema e quadrinhos, alcançando diferentes tipos de público. A representação em Roma, porém, não foi fácil. Segundo Baratto (1977, p. 24) houve uma campanha dos jornais e da Igreja contra a representação da peça, que foi salva pelo público, não pelo amor a Maquiavel, mas para defender a liberdade de expressão e ir contra a censura. A campanha teve apoio do então secretário de oposição do partido comunista Palmiro Togliatti, que na revista Rinascita $n^{\circ} 11$, de 1953, assina com o pseudônimo de Rodrigo de Castiglia para defender em Lucrezia as exigências da mulher moderna. Apesar disso, Mandragola era um texto popular, estudado nas escolas, e provocava reações violentas e polêmicas, não só por mostrar a irreverência do frei, como por mostrar e analisar a burguesia retrógrada, que não queria pensar em assuntos como as estruturas mentais, hábitos familiares, preguiças ideológicas e conformismo, preferindo ignorar problemas sérios e reais. Barattto conclui que o microcosmo cênico de Florença, estilizado e exposto por Maquiavel em sua comédia, se transformava na imagem do macrocosmo da sociedade italiana.

Não faz muito sentido que o público que reagia com tanta violência aos textos de Maquiavel aceitasse sem questionamento os da Commedia dell'Arte, rica em vulgaridade temática e linguística (vulgaridade no sentido burguês do termo). Ao contrário, a pressão do poder político e religioso não impediu o desenvolvimento da Commedia dell'Arte, embora rica em piadas ousadas e cenas triviais, chegando por vezes a favorecer o movimento, e reservando seus próprios limites aos textos escritos, logo inseridos no índice e desaparecendo de circulação.

Retomando a questão da censura, acredita-se que, além da imagem negativa da Igreja, um outro motivo para que a obra houvesse sido censurada foi o seu poder de fazer o público entrar em contato com os problemas de sua sociedade, ao abordar temas como hipocrisia dos costumes familiares e afins, ou o problema das relações cidade-país. O riso é bem-vindo pelo público (substancialmente pequeno-burguês) do qual se fala apenas se não forem tocadas certas estruturas ancestrais bem enraizadas, de uma certa mentalidade social, hábitos e valores que parecem indiscutíveis apenas porque nunca foram questionados. Em outras palavras, Maquiavel e outros, ao atingir em maior ou menor grau o público em suas consciências, atacaram estruturas mentais já cristalizadas em uma determinada classe social: e então o público não parecia mais tão disposto a rir tanto quanto ria de outros programas, aparentemente análogos, revelando, de fato, um mal-estar sintomático. Um dos aspectos que mais chamou a atenção foi o repúdio mais intenso ao fato de a mulher ser adúltera do que à falta de ética e moralidade dos demais personagens, principalmente sua mãe e o frei.

Com o fim da censura em 1970, Maquiavel volta a ser representado, mas o diretor Roberto Guicciardini, na Rassegna Internazionale del Teatro, decide apresentar pela primeira vez em Milão a outra comédia de Maquiavel, Clizia, que embora também apresente questionamentos éticos e morais, é menos crítica e sarcástica que Mandragola, e o público, que esperava o mesmo tipo de humor da obra precedente, não se aborreceu, mas também não se divertiu com a obra, demonstrando certa indiferença em relação à apresentação. 


\section{Considerações finais}

A partir deste percurso de análise, pode-se olhar com novo viés a afirmativa de, na visão do autor, os fins justificarem os meios. Como pôde ser visto, Maquiavel dispunha de visões bastante sólidas e claras de moral e ética, porém estas visões não eram consonantes com as vigentes em sua época, ditadas pela Igreja. Esta divergência de conceitos, que chegavam mesmo a uma imagem positiva do Inferno, também aparece na biografia escrita por Viroli (2002) no qual este expõe o último sonho de Maquiavel: antes de morrer, em 21 de junho de 1527 ele conta a seus amigos que o acompanharam até o último momento sobre o sonho em que diz ter visto um grupo de homens mal vestidos, de aparência miserável e sofredora. Ao indagar quem eram, recebeu a seguinte resposta: "somos os santos e os bem-aventurados, vamos para o Paraíso". Em seguida, avistou uma multidão de homens de nobre e grave aspecto, vestidos com roupas majestosas, que discutiam solenemente sobre importantes problemas políticos. Reconheceu os grandes filósofos e historiadores da Antiguidade que haviam escrito obras fundamentais sobre política e os estados, entre os quais estavam Platão, Plutarco e Tácito. Perguntou também quem eram e para onde se dirigiam: "somos os condenados ao Inferno", responderam. Maquiavel termina seu relato explicando aos amigos que queria antes ir para o Inferno discutir sobre política com os grandes homens da Antiguidade do que ser mandado ao Paraíso, para morrer de tédio na companhia de beatos e santos. Este sonho sintetiza o mundo que ele sempre defendeu: mundo dos homens, da política e da organização do Estado, diferentemente do outro que mostra os "deuses", cuja simbologia da moralidade de céu e inferno nunca o atingiu. Os homens do segundo grupo, segundo Viroli (2002, p. 18) "são condenados ao inferno porque, ao realizar os grandes feitos que os tornaram imortais, violaram as normas da moral cristã”. Mas não é porque não se encaixa na moral cristã que se pode dizer que Maquiavel era ateu ou não religioso. Inúmeras são as citações em seus textos de invocação feitas a Deus, ou interjeições e vocativos demonstrando sinal de respeito, e uma maneira de tratamento apropriado à época. Maquiavel demonstra, a partir de exemplos históricos, que não existe uma moral a priori no que diz respeito à administração pública, e que tudo depende das circunstâncias.

A necessidade de examinar a realidade como ela é forma a essência do pensamento político de Maquiavel. Pode-se concluir que os meios determinam os fins, que manipulando seus personagens para um bem maior, mostra o mundo como ele é com suas possibilidades reais e não como deveria ser, sendo completamente realista, mesmo que para isso exponha os meios baixos e nocivos que a sociedade empregava por debaixo dos panos.

Existe sim em Maquiavel uma ética intrincada, focada em seu pensamento político, sendo, porém, esta uma ética laica, cujas ações individuais não são julgadas pela moralidade, mas pelo efeito político que podem produzir diante de uma situação de fato. Esta postura rompe com o que conhecemos sobre a moral cristã que se baseia em princípios rígidos de bem e mal, de justo e injusto, e isso se reflete tanto em seus escritos políticos quanto em seus personagens.

Assim, sob o ponto de vista maquiaveliano, será moralmente aceitável toda ação que visar 
o bem da comunidade, e isso se reflete também em Mandragola, ainda que de maneira menos óbvia, uma vez que o mundo ali representado é um espelho da visão do autor, deixando claro que a falibilidade humana supera qualquer princípio moral que se queira impor. A ética, vista dessa maneira, pode validar recursos negativos como mal, violência, guerra, tortura, morte, etc. para preservar a harmonia e o bem-estar da sociedade. Novamente retomando Mandragola, pode-se perceber que, embora inteiramente calcada no engano, o resultado é, ao menos na aparência, benéfico para todos os envolvidos, uma vez que todos alcançam seus objetivos.

Assim, podemos concluir que em Mandragola, tudo se resolve através da manipulação, e o próprio fato de que este estado de coisas positivas tenha sido gerado por um engano já evidencia a conhecida visão da ideologia Maquiavélica - se o fim é positivo, qualquer meio para obtê-lo e aceitável, mesmo o engano. Este conceito não só é subentendido como está, inclusive, nas próprias falas dos personagens, como na passagem em que Fra Timoteo destaca: in tutte le cose bisogna guardare al risultato (MACHIAVELLI, 2006, p. 83). Neste ponto, a própria personificação da Igreja Católica Romana, na figura do frei, reconhece que o engano é mais forte do que a virtude ou a fé religiosa, se o resultado da ação for o desejado, e essa é a mensagem principal da obra: a de que os fins justificam quaisquer meios necessários, por mais escusos que pareçam. Este desengano inerente à condição humana é característica marcante na obra, personificada principalmente nos personagens de Fra Timoteo e Sostrata, respectivamente o confessor e a mãe de Lucrezia. Justamente aqueles que deveriam ter sido o alicerce para a jovem esposa, por simbolizarem um, a Igreja Católica Romana e a outra, a família, são justamente aqueles que viriam a ser peças fundamentais para a queda moral e abandono dos valores católicos cristãos de Lucrezia. Entretanto, o pessimismo de Maquiavel não se restringia ao cunho moral ou religioso, mas se mostrava uma decepção secularmente ativa, que se transformava em poderoso otimismo de inteligência e da vontade. Deste modo, Maquiavel se mostra como um grande moralista, ainda que de sua própria concepção de moral, porque, embora convencido de que os homens são o que são - tolos, iludidos, displicentes, falsos, traidores, prontos a vender a própria alma e a alheia - deixava transparecer sua crença de que o homem, se dotado de verdadeira inteligência e de grandes paixões, podia atuar no lodaçal da imoralidade sem com ele se confundir. 


\section{Referências}

ASOR ROSA, A. Storia europea della letteratura italiana. Torino: Einaudi, 2009.

BARATTO, M. La commedia del Cinquecento. Vicenza: Neri Pozza, 1977

COIMBRA, J. A. A. Fronteiras da ética. São Paulo: Senac, 2002.

MACHIAVELLI, N. La Mandragola. (org. P. Stoppelli). Milano: Mondadori, 2006

PULCE, G. Saggio storico di letteratura poetica dal secolo di Pericle fino al nostro. Napoli: Stamperia del Fibreno. 1867.

PROCACCI, G. Machiavelli nella Cultura Europea dell'Età Moderna. Roma-Bari: Laterza, 1995. RIDOLFI, R. Vita di Niccolò Machiavelli. Firenze: Sansoni Editore, 1978.

STOPPELLI, P. La Mandragola. Storia e filologia. Roma: Bulzoni, 2005

VIROLI. M. O sorriso de Nicolau - História de Maquiavel. Trad. de Valéria Silva. São Paulo: Ed. Estação Liberdade, 2002.

Recebido em: 05/10/2020

Aprovado em: 11/11/2020 